\title{
Antithrombotic therapy in cardiac surgery
}

\section{[Traitement antithrombotique en chirurgie cardiaque]}

André Vincentelli MD, ${ }^{*}$ Brigitte Jude MD, † Sylvain Bélisle MD‡

Purpose: To review the perioperative management of antithrombotic therapy in cardiac surgery, including the management of cardiopulmonary bypass (CPB) and off-pump surgery.

Methods: A review of the relevant English literature over the period 1975-2005 was undertaken, in addition to a review of international practices in antithrombotic therapy in cardiac surgery.

Principal findings: Cardiopulmonary bypass is required in most procedures and makes anticoagulation mandatory. Anticoagulation is, usually, achieved with unfractionnated heparin (UFH). Unfractionated heparin is monitored by point-ofcare (POC) testing, such as the activated clotting time or the determination of heparin concentration. The target values of both tests remain empirical, with no clearly validated thresholds. The target value needs to be adjusted according to the POC test, given significant variations between devices and activators. After CABG, the need for antiplatelet therapy is well demonstrated, in order to limit the risk of postoperative death or ischemic events, and improve venous graft patency. Immediately after valvular surgery, antithrombotic therapy should take into account the specific risk carried by each patient and by each prosthetic device. The risk of venous thromboembolism, though poorly defined, is also present in the postoperative period and may require additional attention. Given the frequent exposure to UFH, occurrence of heparininduced thrombocytopenia is not infrequent in these patients and requires careful individual management.

Conclusions: Antithrombotic therapy is an essential component of cardiac surgery. Yet, with the exception of antiplatelet agents in CABG patients, antithrombotic therapy is often based on the clinical experience of medical teams more than on an evidence-based assessment of the literature.
Objectif: Revoir la gestion périopératoire du traitement antithrombotique en chirurgie cardiaque, incluant la circulation extracorporelle (CEC) et la chirurgie à cœur battant.

Méthode : Une revue des articles pertinents publiés en anglais de 1975 à 2005 a été entreprise en plus d'une revue des pratiques internationales de traitement antithrombotique en cardiochirurgie.

Constatations principales: La circulation extracorporelle est nécessaire pour la majorité des opérations et rend l'anticoagulation obligatoire. L'anticoagulation est, habituellement, réalisée avec de l'héparine non fractionnée (HNF). L'HNF est contrôlée par des tests faits au chevet du malade comme le temps de coagulation activée ou la détermination de la concentration d'héparine. Les valeurs cible des deux tests demeurent empiriques, sans valeurs seuil clairement validées. La valeur cible doit être ajustée en fonction de chaque test de chevet à cause des variations significatives entre les instruments et les activateurs. Après le pontage aortocoronarien (PAC), la nécessité d'un traitement antiplaquettaire a été bien démontrée, qui vise à limiter les décès postopératoires ou les incidents ischémiques et à améliorer la perméabilité du greffon veineux. Immédiatement après la chirurgie valvulaire, le traitement antithrombotique doit tenir compte du risque spécifique à chaque patient et à chaque prothèse. Le risque de thromboembolie veineuse, bien que peu défini, est aussi présent en période postopératoire et peut nécessiter une attention supplémentaire. Étant donné l'exposition fréquente à l'HNF, l'occurrence de thrombopénie induite par l'héparine n'est pas rare chez ces patients et exige une prise en charge individuelle particulière.

Conclusion : Le traitement antithrombotique est une composante essentielle de la chirurgie cardiaque. Néanmoins, à l'exception des antiplaquettaires chez les patients qui ont subi un PAC, le traitement antithrombotique repose souvent sur l'expérience clinique des équipes médicales plus que sur l'évaluation fondée sur les données de la recherche.

From the Centre Hospitalier Régional Universitaire de Lille, Clinique de Chirurgie Cardiovasculaire; ${ }^{*}$ the Institut d'HématologieTransfusion;† Université de Lille, Lille, France; and the Institut de Cardiologie de Montréal et Centre Hospitalier de l'Université de Montréal (CHUM), ‡ Département d’Anesthésiologie de l’Université de Montréal, Montréal, Québec, Canada.

Address correspondence to: Dr. Brigitte Jude, Laboratoire d'Hématologie, Hôpital Cardiologique, 59037, Lille cedex, France. E-mail: b-jude@chru-lille.fr 
A NTITHROMBOTIC therapy is a keystone for the safe conduct of effective cardiac operations. Most procedures require cardiopulmonary bypass (CPB), which induces hemostatic activation, and renders optimal anticoagulation mandatory in order to avoid both thrombotic and hemorrhagic complications. Postoperative antithrombotic therapy is also essential in order to improve coronary artery graft patency, limit the risk of thrombosis on cardiac prosthetic devices and of thrombotic complications secondary to arrhythmias. Of note, the risk of venous thromboembolic complications, though poorly defined in this context, is also present in the postoperative period. Unlike other surgeries, the use of antithrombotic agents in this context is often based on the experience of the anesthetic and surgical teams, more than on the results of large prospective controlled studies.

\section{Anticoagulation during cardiac surgery Anticoagulation for $C P B$}

The potent activation of coagulation induced during $\mathrm{CPB}$ renders an effective and profound anticoagulation mandatory. High doses of unfractionated heparin $(\mathrm{UFH})$ remain the gold-standard to achieve this objective. Macromolecular heparin is formed by the combination of a core protein with a variable number of mucopolysaccharide chains. The anticoagulant activity of UFH is, primarily, related to its ability to complex with antithrombin through a specific pentasaccharide sequence. Long chains accelerate the inhibition of thrombin (anti-IIa activity or anticoagulant property). Smaller fragments, below 16 to 20 monosaccharide units, inhibit only activated factor $\mathrm{X}$ and reduce the generation of thrombin (anti-Xa activity or antithrombotic property). Unfractionated heparin has an anti-IIa/anti-Xa ratio of $1: 1$. Once the inhibition reaction is completed, heparin is released and available to promote a new antithrombin-thrombin complex. Protamine neutralizes the anti-IIa activity of UFH more efficiently than its anti-Xa activity.

Pharmaceutical grade UFH is a heterogeneous mix of polysaccharides produced either from pork intestinal mucosa or beef lung. Beef lung heparin is no longer used in European countries in order to minimize the theoretical risk of acquiring variant CreutzfeldJacob disease, and its use seems mostly restricted to the USA. Unfractionated heparin has a rapid onset of action, a short but variable half-life (from $30 \mathrm{~min}$ for $25 \mathrm{IU} \cdot \mathrm{kg}^{-1}$ to $150 \mathrm{~min}$ for $\left.400 \mathrm{IU} \cdot \mathrm{kg}^{-1}\right) .{ }^{1}$ During $\mathrm{CPB}$, the in vivo predominant action of $\mathrm{UFH}$ is through its anti-IIa activity. ${ }^{2}$ Most often, the initial dose of heparin, before the onset of CPB, is calculated according to the patient's weight. North-American practice favours a dosage of $300 \mathrm{IU} \cdot \mathrm{kg}^{-1}$ in $67 \%$ of centres and $400 \mathrm{IU} \cdot \mathrm{kg}^{-1}$ in $16 \% .{ }^{3}$ Additional boluses of heparin $(5,000$ to $10,000 \mathrm{IU})$ are, subsequently, administered either systematically (about once per hour), or according to the results of coagulation monitoring. A continuous infusion may improve the stability of the heparin concentration during $\mathrm{CPB}{ }^{4}$

The use of UFH carries a significant limitation during CPB. After a standard dose (per kg) of UFH, the activated clotting time (ACT), heparin concentration and biological half-life range from 200 to $600 \% .^{5}$ Several authors failed to observe a correlation between the dose of UFH and the anti-Xa concentration or the ACT. ${ }^{6-10}$ The pharmacokinetic and pharmacodynamic properties of UFH are highly variable, with large standard deviations, and show significant variations between individual responses according to inflammatory status, hepatic and renal functions. , $11,12^{2}$ Considering these large differences, an appropriate and individual monitoring of the anticoagulant effect of UFH is mandatory. Such monitoring is used widely, although it has not been definitely demonstrated that it improves outcome. Moreover, the target value of a coagulation test that would translate into a hypothetical "optimal anticoagulation level" during $\mathrm{CPB}$ remains to be defined.

Point-of-care (POC) heparin monitoring during CPB Heparin monitoring is usually achieved with POC tests conducted on whole blood. The anticoagulant activity of UFH is appreciated by the appearance of a clot in the sample and measured either in seconds or converted in units of activity per mL. The most common POC tests are the ACT (measured in seconds) and heparin concentration monitor (results expressed in IU. $\left.\mathrm{mL}^{-1}\right) .{ }^{13}$ The ACT measures the clotting time of whole blood in the presence of a contact phase activator (celite or kaolin). The ACT is a good reflection of high antithrombin (anti-IIa) activity. ${ }^{6}$ Heparin concentration monitoring by POC tests is based on a protamine titration curve that evaluates the anti-IIa activity of heparin (anticoagulant activity). The "classic" heparin concentration test, done in coagulation laboratories and performed on plasma, measures the anti-Xa activity (antithrombotic activity) of UFH. The ACT vs heparin concentration debate is resolved if the clinician understands that both instruments measure a biological action of heparin, in a different way. However, an important question remains: which threshold should we target during CPB? 


\section{Monitoring of anticoagulation by the ACT during $C P B$}

Among the various devices available, the most widely used are the Hemochron ${ }^{\circledR}$ (International Technidyne Corporation, Edison, NJ, USA) and the ACT II ${ }^{\circledR}$ (Medtronic, Medtronic, Parker, CO, United States). ${ }^{3,14}$ Widely accepted target values for the ACT during CPB are $480 \mathrm{sec}$ ( $41 \%$ of centres) or $400 \mathrm{sec}$ ( $32 \%$ of centres). ${ }^{3}$ The $480-\mathrm{sec}$ threshold is based on an in vitro study. ${ }^{6}$ Importantly, this arbitrary target of eight minutes was proposed for an instrument (the manual ACT) different from those used currently. The 400 -sec target is supported by an animal study demonstrating that fibrin monomers were produced when the Hemochron ${ }^{\circledR}$ celite ACT was less than $400 \mathrm{sec}^{15}$ Of note, preservation of fibrinogen and platelets at the end of CPB was improved significantly in animals with an ACT > $750 \mathrm{sec}$. A target value of $400-480 \mathrm{sec}$ has been proposed only for the Hemochron ${ }^{\circledR}$-based instrument. ${ }^{16}$ Modifications of the blood salvage procedure (avoiding the re-infusion of shed mediastinal blood, or return after washing and centrifugation via a cell-saving device) or the use of heparin-bound circuits could limit blood activation and reduce the amount of heparin required. ${ }^{17-21}$

The ACT values obtained by different monitors or with different activators cannot be interchanged, particularly during anticoagulation with heparin. ${ }^{22}$ A comparative study in patients undergoing percutaneous coronary angioplasty showed that the results of the ACT $\mathrm{II}{ }^{\circledR}$ were $130 \mathrm{sec}$ shorter than those of the Hemochron ${ }^{\circledR}$ ACT. In the therapeutic range, the mean difference in results between the two devices was $30 \% .^{23}$ Another recent study, which compared two POC devices (Hemochron Response ${ }^{\circledR}$, International Technidyne Corporation, Parker, CO, USA and Aktalike ${ }^{\circledR}$, Array Medical, Somerville, NJ, USA) to the older Hemochron $801{ }^{\circledR}$ showed that the ACTs measured with the Aktalike ${ }^{\circledR}$ were $18 \%$ shorter than those measured with the Hemochron $801 \AA(P$ $=0.0001) .{ }^{24}$ The ability to detect a clot in the blood sample is, obviously, different between instruments and has an impact on the final result.

The ACT values depend not only on the type and amount of coagulation activator used (celite or kaolin) but also on the presence of other drugs. Aprotinin increases the celite-based ACT in a dose-dependent manner, while the measure of the kaolin-based ACT (Hemotec, Medtronic-HemoTec, Englewood, CO, USA) is not prolonged. ${ }^{25-27}$ The increase of the celite ACT may, possibly, reflect aprotinin's own anticoagulant effect, in addition to that of heparin. ${ }^{28}$ When aprotinin is used during $\mathrm{CPB}$, the recommended empirical target value for the celite ACT is at least $750 \mathrm{sec}$, while it is $450 \mathrm{sec}$ for the kaolin-ACT. ${ }^{23}$ It is important to note that the target of $750 \mathrm{sec}$ is based on in vitro data and that the threshold of $450 \mathrm{sec}$ for the kaolin-ACT has not been validated by clinical studies. ${ }^{29}$ Tranexamic acid does not modify ACT values, making anticoagulation easier to manage when POC monitors are used to monitor heparin effect. ${ }^{30}$

For clinical purposes and until randomized trials become available, UFH should be administered to keep the celite Hemochron ${ }^{\circledR}$ above $400 \mathrm{sec}$. In patients receiving aprotinin a target of $750 \mathrm{sec}$ or more should be used. Reinterpretation of the results from Young et al. ${ }^{15}$ suggests that a safer threshold of more than $750 \mathrm{sec}$ should, probably, be used in the majority of patients.

An ACT is, usually, obtained before the onset of CPB (baseline ACT), five minutes after the administration of heparin, every $30 \mathrm{~min}$ during the procedure, and after the neutralization of heparin with protamine. The optimal time to determine the baseline ACT is immediately after the surgical incision. ${ }^{31}$

Overall, the optimal target value of the ACT remains empirical, even when using the most common device (Hemochron ${ }^{\circledR}$ celite) as no large prospective study has clearly validated a threshold. Importantly, the target value applied during $\mathrm{CPB}$ needs to be individualized, as no single number can be applied to all POC monitors and activators. An evidence-based approach to optimal anticoagulation during cardiac surgery would require clinical studies, evaluating bleeding and thrombotic complications. These studies should also take into account the important variation of the results obtained during CPB or off bypass surgery and differences between devices and activators. ${ }^{16}$ Until randomized clinical trials become available, the clinician will have to apply an empirical threshold, adapted to the POC monitor being used.

\section{Monitoring of heparin concentration during CPB}

During $\mathrm{CPB}$, heparin activity (usually described as heparin concentration) can be determined by the protamine neutralization test in activated whole blood. $^{32-34}$ Heparin concentration during $\mathrm{CPB}$ is most often determined by POC monitors such as the Hepcon HMS ${ }^{\circledR}$ (Medtronic, Parker, CO, USA). As for ACT monitors, the time for formation of a clot is measured. This result is translated in units per $\mathrm{mL}$, based on a predetermined heparin/protamine neutralization ratio that varies from 0.8 to 1.3 . The chosen ratio in the test tube depends on the type and lot of heparin used by the clinician. A clinical dosage of heparin or protamine can be proposed by the instru- 
ment, based on the estimated blood volume. These numerous assumptions can introduce a large bias in the final measure and limit the extrapolation of results between centres.

The protamine neutralization test is different from the measurement of chromogenic anti-Xa activity of heparin conducted on plasma. The correlation between the protamine titration method and the enzymatic determination of heparin levels remains controversial. ${ }^{34-36}$ While they may correlate, the results are not interchangeable.

The optimal heparin concentration during $\mathrm{CPB}$ has not been well established. The North American practice is to maintain a concentration of at least 3.0 $\mathrm{IU} \cdot \mathrm{mL}^{-1}$ (in $64 \%$ of centres) or $3.5 \mathrm{IU} \cdot \mathrm{mL}^{-1}$ (in $19 \%$ of centres). ${ }^{3}$ These concentrations remain empirical, and their maintenance has no clinical advantage over an ACT-based management. ${ }^{37,38}$

The instrument may also determine an individualized target concentration of heparin. Prior to $\mathrm{CPB}$ (with its associated hypothermia, hemodilution and consumption of coagulation factors), a value of heparin concentration is correlated to a target kaolin ACT. During CPB, a heparin concentration will be used as a surrogate for the ACT to adjust heparin and protamine dosages. Contrary to an arbitrary target, the heparin concentration determined in this manner is different from patient to patient. This practice is associated with the administration of a larger dose of heparin, a smaller dose of protamine (protamine/ heparin ratio of 0.7 ) and a significant reduction in the transfusion of hemostatic blood products (plasma, platelet concentrates and cryoprecipitate). ${ }^{39}$ However, a more recent study has not been able to confirm these favourable results. ${ }^{37}$

As for the determination of the optimal ACT value, only studies addressing clinical outcomes would be valuable. A recent prospective study indicated that heparin monitoring with the Hepcon HMS ${ }^{\circledR}$ device led to maintenance of higher heparin levels, but postoperative bleeding was not decreased. ${ }^{37}$ There is no evidence that an ACT-based administration of heparin is better than a heparin concentration-based management. ${ }^{40}$ This important question should be addressed before considering the addition of antithrombin concentrates in order to achieve "adequate" prolongations of the ACT, as suggested recently. ${ }^{41}$

\section{Heparin resistance and antithrombin concentrates}

Heparin resistance is defined as an insufficient prolongation of the ACT after the administration of heparin. The definition of heparin resistance varies between studies: either an ACT under $600 \mathrm{sec}$ after the infu- sion of $600 \mathrm{IU} \cdot \mathrm{kg}^{-1}$ or an ACT under $480 \mathrm{sec}$ after the infusion of $450 \mathrm{IU} \cdot \mathrm{kg}^{-1} \cdot{ }^{42,43}$ In such cases, antithrombin deficiency is suspected as a large part of the anticoagulant activity of heparin requires the presence of antithrombin. During CPB, antithrombin levels are frequently around $60 \%$ of normal (due to hemodilution, elimination of the heparin-antithrombin and antithrombin-proteases complexes). It was suggested initially that heparin resistance was more frequent in patients receiving heparin prior to surgery, but this was not confirmed subsequently. ${ }^{41,44}$ Acquired antithrombin deficiency can lead to decreased inhibition of thrombin and factor Xa activity by heparin. ${ }^{45-47}$

Predictably, antithrombin infusion results in ACT prolongation. ${ }^{41}$ Interestingly, treatment with antithrombin could also decrease hemostatic activation markers. It has been suggested that antithrombin repletion could be specially beneficial in children, where CPB induces severe hemodilution. ${ }^{46,47}$ However, no clinical study has yet demonstrated a clinical benefit or evaluated the cost/benefit ratio of this additional form of anticoagulation. Moreover, as the ideal target ACT during CPB is not well defined, the infusion of antithrombin should not aim to solely increase the ACT but should be supported by a clear demonstration of improved clinical outcomes.

Anticoagulation for beating heart (off-pump) surgery Initially, the absence of exposure to a $\mathrm{CPB}$ circuit supported the use of a "vascular surgery" target of $250 \mathrm{sec}$ for the ACT. Usually, a bolus of $100 \mathrm{IU} \cdot \mathrm{kg}^{-1}$ of UFH is administered. However, a more recent approach favours higher thresholds. In interventional cardiology, the maintenance of an ACT of 300 to $400 \mathrm{sec}$ provides the best balance between the rate of bleeding and thrombotic complications. A recent study compared a more aggressive anticoagulation management to a control group where the ACTs were maintained $>300 \mathrm{sec}$ (heparin dose of 150 IU. $\left.\mathrm{kg}^{-1}\right) .{ }^{48}$ The experimental group received an initial bolus of heparin of $300 \mathrm{IU} \cdot \mathrm{kg}^{-1}$ and ACT values were maintained higher than $400 \mathrm{sec}$. This protocol was associated with a reduced rate of postoperative graft thrombosis $(5.2 \%$ vs $1.3 \%, P<0.05)$. Based on limited data and extrapolating from interventional cardiology, the ACT should probably be maintained at more than $400 \mathrm{sec}$ with an appropriate dose of UFH.

\section{Postoperative antithrombotic therapy}

The period after cardiac surgery carries both a high risk of bleeding and thrombotic complications. Given the increasing age and the high prevalence of atherosclerotic disease in this population, postoperative 
arterial thrombotic events such as myocardial infarction and stroke are a major concern. Specific arterial complications consist of peripheral embolization in non-sinus rhythm patients, graft occlusion in CABG and valve thrombosis in valvular surgery. Venous complications such as deep vein thrombosis (DVT) or pulmonary embolism may also occur in the postoperative course, as in other major surgical procedures. The aim of postoperative antithrombotic therapy is to minimize the rate of adverse thrombotic events (arterial or venous), without an excessive increase in bleeding rate and exposure to transfusions.

Antiplatelet therapy in the prevention of graft occlusion and other arterial complications after $C A B G$

The risk of early graft closure, mostly restricted to saphenous vein grafts, is real and clearly multifactorial. ${ }^{49}$ In the absence of antithrombotic therapy, the percentage of venous graft patency, evaluated between the first month to 24 months after CABG surgery ranges from 19.7 to $91 \%$ (mean $75.3 \%$ ). ${ }^{49}$ In contrast, the rate of the internal mammary artery graft patency is high, from 92 to $100 \%$ at three months to three years after surgery, even in the absence of antiplatelet therapy. ${ }^{50,51}$ Acetyl salicylic acid (ASA) therapy improves the rate of venous graft patency. ${ }^{52-55}$ The early introduction of ASA (on the day of surgery) is more effective than a late one (after three days), suggesting that graft occlusion is an early thrombotic process mediated by platelet aggregation. ${ }^{56-58}$ Acetyl salicylic acid 75 to $325 \mathrm{mg}$ within six hours after the operation, or as soon as possible in the case of bleeding, is recommended. ${ }^{49,52,59,60}$ It should be noted that two out of three studies evaluating a low dose of ASA (100-150 mg) showed no clinical benefit. In contrast, three out of four studies report an improved graft patency rate with $325 \mathrm{mg}$ of ASA.

In patients already receiving ASA before CABG, the discontinuation of treatment before CABG is matter of debate. The preoperative use of ASA was found to increase postoperative blood loss, transfusion requirements and early reoperation for bleeding. ${ }^{61-63}$ However, these findings were inconsistent and of a weak magnitude. ${ }^{64}$ Recent guidelines indicate that cessation of aspirin and other platelet inhibitors seven to ten days before CABG in stable patients and lowrisk plaque morphology could be prudent to decrease the risk of postoperative bleeding and transfusion. ${ }^{60}$ However, a recent large prospective case-control study showed that the preoperative use of ASA was associated with a decreased risk of mortality, without a significant increase of hemorrhage, and that the benefits of ASA overweigh the risk of bleeding. ${ }^{65} \mathrm{~A}$ recent observational study showed that early (i.e., within $48 \mathrm{hr}$ ) ASA therapy after CABG was associated with a reduction of 44 to $70 \%$ in the frequency of early death, and of major adverse events related to the heart, brain, kidney and gastrointestinal tract. ${ }^{66}$

Clopidogrel, another antiplatelet agent, has also been proposed after CABG, as an alternative for patients who are allergic to ASA. The recommended dose is a loading dose of $300 \mathrm{mg}$, six hours after surgery, followed by $75 \mathrm{mg}$ id. ${ }^{52}$ The benefits and risks of clopidogrel were analyzed recently in patients undergoing CABG for non-ST elevation acute coronary syndrome. ${ }^{67}$ The benefits of clopidogrel (re-introduced after six to 25 days after surgery) overweighed the bleeding risk. However, data indicate that the use of clopidogrel within three to five days before surgery is associated with increased bleeding. ${ }^{67}, 68$ Therefore, cessation of clopidogrel at least five days before surgery, when possible, is clearly recommended. When clopidogrel has not been stopped before surgery (for example, emergency procedure), the use of antifibrinolytics (aprotinin, epsilon-aminocaproic acid or tranexamic acid) could be proposed, since such treatments decrease postoperative blood loss and transfusion requirements, without increasing early graft closure ${ }^{69-77}$ More recently, it was emphasized that ASA or clopidogrel resistance was common after CABG, suggesting the possible need for adjusted dosage or alternative therapy in such patients. ${ }^{78-80}$ The combination of ASA with dipyridamole or vitamin $\mathrm{K}$ antagonists is not recommended for the prevention of postoperative graft thrombosis. ${ }^{52}$

\section{Antithrombotic therapy after valvular surgery}

Patients undergoing valve surgery are at risk of developing valvular and arterial thrombosis. This risk is especially high in patients with a mechanical prosthetic heart valve, justifying life-long oral anticoagulation, but is also increased in patients with biological heart valves or after valve repair. Guidelines for long-term anticoagulation in these patients have been proposed by scientific societies such as the American College of Cardiology/American Heart Association, the European Society of Cardiology, and the American College of Chest Physicians. ${ }^{81-83}$ Lifelong oral anticoagulation is required for all patients with a mechanical valve prosthesis, aiming for a target international normalized ratio (INR) of the prothrombin time greater than 2 . The definitive target value will vary according to the position of the valve (higher target values are required for mitral prostheses compared to aortic), the type of prosthesis (higher target values are required for first generation prostheses 
compared to recent devices), and the cardiac context (higher target values are required in the presence of arrhythmia or auricular dilatation). The European and American recommendations are, overall, identical for aortic valve prostheses (INR between 2 and 3 for second generation prostheses in the absence of auricular dilatation or arrhythmia). For mitral valve prostheses, the European guidelines recommend higher INR values than the American ones (3-4.5 and 2.5-3.5, respectively). For biological mitral valves, oral anticoagulation is recommended during the first three months after surgery. ${ }^{83}$ Whether biological aortic valve prostheses require oral anticoagulation during the first three months remains a matter of debate. A recent study suggests that warfarin is not more effective than ASA with regards to early cerebral ischemic events, bleeding and survival. ${ }^{84}$ Whatever the long-term target value at which the INR should be maintained, the need for early antithrombotic therapy after surgery is recognized, since thrombotic events can occur in the very first days after surgery. Initially, heparins are used to achieve therapeutic levels of anticoagulation. As the risk of bleeding is high in the first days after surgery, heparin is usually started six hours after surgery, or later in the case of bleeding. A vitamin $\mathrm{K}$ antagonist is initiated 24 to $48 \mathrm{hr}$ after chest drainage tubes are removed. Unfractionated heparin is most often prescribed after valve surgery, since low molecular weight heparins (LMWH) have not been evaluated extensively in these conditions. The dose of UFH is adjusted according to coagulation monitoring (usually the activated partial thromboplastin time; aPTT), aiming for an aPTT 1.5 to 3 longer than control. Unfractionated heparin must be continued until the INR is in the therapeutic range. Given the difficulties and cost of UFH management during the period between the end of surgery and effective anticoagulation with a vitamin $\mathrm{K}$ antagonist, an increasing number of cardiac surgery units use LWMH, although the available evidence of their efficacy and safety is still limited. A non-randomized study of 208 patients undergoing mechanical heart valve implantation showed that LMWH (mostly enoxaparin $200 \mathrm{UI} \cdot \mathrm{kg}^{-1}$ per day) was as safe and effective as UFH. ${ }^{85}$ No difference in the rate of bleeding or thrombotic complications was observed with enoxaparin in a small cohort (29) of patients, but two bleeding complications were reported in another 12 patients. ${ }^{86,87}$ Therefore, the use of $\mathrm{LMWH}$ in the immediate postoperative period after heart valve surgery remains controversial. If LMWH are used, anti-Xa activity must be monitored carefully, and the dosage should be adapted according to the renal function of the patient.
Other indications for heparin or vitamin $K$ antagonists Anticoagulation using heparin or vitamin $\mathrm{K}$ antagonists can be required in patients with atrial fibrillation after CABG. New-onset postoperative atrial fibrillation occurs in $30 \%$ of patients with a peak incidence on the second to third postoperative day. Postoperative atrial fibrillation is associated with a two- to threefold increase in postoperative risk for stroke. ${ }^{60}$ The risk of aggressive anticoagulation in such patients (mediastinal bleeding) has to be weighed against the possible reduction of neurological complications. Alternatively, electrical or pharmacological cardioversion, without anticoagulation, can be attempted, especially if a left atrial thrombus has been excluded. ${ }^{60}$ Beyond the early postoperative period, cardioversion can be attempted in patients receiving $i v$ heparin. If atrial fibrillation persists more than $48 \mathrm{hr}$, warfarin anticoagulation is recommended for at least four weeks. ${ }^{88}$ Also, longterm (three to six months) anticoagulation is suggested for patients with recent anterior-apical myocardial infarction and persistent wall-motion abnormality. ${ }^{60}$

Heparin or vitamin $\mathrm{K}$ antagonists can also be required to prevent the risk of venous thromboembolism, which is present after CABG, but remains poorly defined. In the absence of heparin prophylaxis, the incidence of DVT was $22 \%$ in the prospective study by Goldhaber et al. ${ }^{89}$ The incidence of pulmonary embolism ranges from 0.6 to $9.5 \% .{ }^{90-92}$ Eighteen to $40 \%$ of pulmonary embolisms were fatal. A recent observational study, from three Italian rehabilitation institutions serving 19 cardiac surgery units, indicates that despite short-duration (< three days) heparin prophylaxis after CABG (mainly LMWH) in $63 \%$ of the patients, deep venous thrombosis was present in $17.4 \%$ of cases. Proximal vein thrombosis accounted for $2.6 \%$ of cases, and pulmonary embolism was observed in $0.7 \%$. Ninety-one percent of the DVT were diagnosed on admission, and $50 \%$ were localized in the saphenous vein controlateral to the harvest site. ${ }^{93}$ Overall, these data suggest that CABG is associated with a moderate but significant risk of venous thromboembolism. The efficacy of mechanical prevention seems poor. ${ }^{89,93}$ The safety and efficacy of LWMH have not been evaluated in this context, but LMWH should probably be considered in the postoperative period, especially in patients with additional risk factors such as prolonged length of stay and female gender. ${ }^{93}$

\section{Management of heparin-induced thrombocytope- nia (HIT)}

Cardiac surgery patients commonly receive UFH treatment either during $\mathrm{CPB}$ and/or in the postoperative period, putting them at relatively high risk for HIT. 
Heparin-induced thrombocytopenia is an immunemediated disorder resulting from the production of immunoglobulin $\mathrm{G}$ ( $\mathrm{IgG}$ ) antibodies that recognize the heparin-platelet factor 4 (PF4) complex. ${ }^{94,95}$ This multimolecular complex of IgG-PF4-heparin can bind to the immunoglobulin fragment $\mathrm{c}(\mathrm{Fc})$ platelet receptor, leading to platelet activation. The thrombotic risk remains elevated for days to weeks, even after heparin has been stopped. ${ }^{96}$ Heparin antibodies triggered by the recent heparin exposure are transient. ${ }^{97}$ The overall frequency of HIT after cardiac surgery is approximately 2 to $3 \%{ }^{98,99}$ However, immunoglobulin seroconversion after cardiac surgery is present in $30 \%$ to $50 \%$ of patients, indicating that only a minority of antibodypositive patients develop thrombocytopenia. Heparininduced thrombocytopenia has been shown to be more frequent when UFH from beef lung rather than from porcine gut is used. ${ }^{100}$ Heparin from pork intestinal mucosa is the recommended formulation to be used during cardiac surgery. ${ }^{101}$ Low molecular weight heparin, which is not commonly used during heart surgery because of its long half-life and poor neutralization by protamine, carries a lower risk of HIT than UFH. ${ }^{102}$

A proportional fall in platelet count of more than 30 to $50 \%$ from the highest preoperative value, five to ten days after heart surgery, with or without thrombosis, suggests HIT. ${ }^{103,104}$ Significant levels of HIT antibodies usually occur only after the fifth postoperative day or later, so thrombocytopenia during the first four postoperative days is only rarely attributable to HIT. The risk of thrombosis is high, with 40 to $75 \%$ of patients developing this complication. ${ }^{96}$ In cardiac surgery patients developing HIT, arterial is more frequent than venous thrombosis (mainly lower limb arteries)..$^{98,104}$ Saphenous vein graft occlusion is a prominent manifestation of HIT ${ }^{105}$ since it is present in $38 \%$ to $81 \%$ of the cases with an associated mortality of $28 \%{ }^{98,99}$ Deep vein thrombosis (especially associated with central venous catheters) and pulmonary embolism are also common. ${ }^{106}$

\section{Laboratory testing}

Platelet aggregation assays have limited sensitivity and specificity for detecting HIT antibodies. ${ }^{94,107}$ An enzyme-linked immunosorbent assay (ELISA) detecting anti PF4-heparin antibodies is highly sensitive for HIT, meaning that a negative result usually rules out the condition. However, ELISA has a moderate positive predictive value, particularly if the test result is weakly positive. A high rate of sub clinical HIT antibodies after cardiac surgery, without thrombocytopenia, is observed. The serotonin-release test is more predictive of HIT but the test can only be performed in highly specialized centres. ${ }^{108}$ All these assays are carried out in reference laboratories, and the results are rarely obtained without delay. This means that the decision to stop heparin and to switch to an appropriate antithrombotic therapy has to be taken on the basis of a decline of the platelet count and the clinical context (typically five to ten days after surgery, with or without thrombosis or other clinical manifestation).

\section{Alternative anticoagulant therapies}

Alternative anticoagulant therapies are: 1) hirudins and other direct thrombin inhibitors (Lepirudin in the United States, Canada, European Union, Australia and New Zealand; Bivalirudin in the United States; Argatroban in the United States and Canada); and 2) danaparoid, a factor $X a$ inhibitor available in the European Union, Canada, Australia and New Zealand.

\section{Direct thrombin inhibitors}

Hirudin is naturally produced by the salivary gland of the medicinal leech. Lepirudin (Refludan ${ }^{\circledR}$, Berlex Montville NJ, USA and Pharmion, Cambridge, UK) is available by recombinant technology. Hirudin forms an irreversible complex with thrombin, inhibiting all procoagulant actions of thrombin. No antidote is available. In patients with a normal renal function, the half-life is approximately $80 \mathrm{~min}$, and hirudin levels decline quickly after stopping the infusion. When renal function is impaired, the half-life increases to up to more than $200 \mathrm{hr}$. Drug accumulation can cause severe bleeding and ultrafiltration may be required (using appropriate filters). ${ }^{109,110}$ Lepirudin has been used during $\mathrm{CPB}$ at high doses. It can only be monitored by the ecarin clotting time (ECT) since the ACT and aPTT do not correlate with the concentration of hirudin. The goal is to achieve stable intraoperative hirudin levels of 3.5 to $4 \mu \mathrm{g} \cdot \mathrm{mL}^{-1}{ }^{111}$ Dosing schedules and treatment protocols are presented in detail elsewhere. ${ }^{112}$

Bivaluridin (Angiomax ${ }^{\circledR}$ (ICS, Louisville, KY, USA) is a synthetic peptide modelled after hirudin which, unlike lepirudin, interacts reversibly with thrombin and has a short half-life $(25 \mathrm{~min})$. Its clearance is mediated by proteolytic cleavage by plasma enzymes (including thrombin). Clearance is also reduced when renal function is impaired. Bivalirudin has been used successfully for anticoagulation during both off-pump and on-pump cardiac surgery in patients with acute or previous HIT. ${ }^{113-115}$ Clots can be observed in the pericardial cavity and should not be interpreted as a sign of insufficient systemic anticoagulation. Ecarin clotting time is recommended for intraoperative monitoring during $\mathrm{CPB} .{ }^{115}$ 
Argatroban is a direct thrombin inhibitor, eliminated by the liver with a half-life of 40 to $50 \mathrm{~min}$. No specific antidote is available. Argatroban interferes with the prothrombin time and INR, which can be confusing when vitamin $\mathrm{K}$ antagonists are used. It has been used successfully during CPB in dogs, but clinical experience in humans is too limited ${ }^{116}$ to be recommended.

\section{Danaparoid}

Danaparoid (Orgaran ${ }^{\circledR}$, Organon, Oss, The Netherlands) is a glycosaminoglycan with predominant anti-factor Xa activity, and low cross-reactivity with HIT antibodies. It has a long half-life $(25 \mathrm{hr})$ and no antidote is available, making postoperative bleeding a major concern after $\mathrm{CPB}$. Only the anti-factor Xa levels can be used to monitor danaparoid levels required for CPB. Fixed dose or weight-adjusted regimens have been proposed, with a target anti-factor Xa level of $1.5 \pm 0.3 \mathrm{U} \cdot \mathrm{mL}^{-1}$. 117,118

\section{Heparin and tirofiban}

An interesting alternative treatment by UFH and the short-acting platelet glycoprotein IIb-IIIa antagonist tirofiban (Aggrastat ${ }^{\circledR}$, Merck and co, Frankfurt, Germany) has been proposed by Koster et al. in 2001. ${ }^{119}$ In a report on 47 patients with HIT and $\mathrm{CPB}$, this strategy (UFH bolus $400 \mathrm{IU} \cdot \mathrm{kg}^{-1}$ and tirofiban, bolus $10 \mu \mathrm{g} \cdot \mathrm{kg}^{-1}$, followed by a continuous infusion $0.15 \mu \mathrm{g} \cdot \mathrm{kg}^{-1} \cdot \mathrm{min}^{-1}$ ) resulted in satisfying results, with no excessive bleeding and no thrombotic complications. Only three patients presented a severe thrombocytopenia before $\mathrm{CPB}$, and received platelet concentrates. Hirudin was used as pre- and post-CPB antithrombotic treatment. The important advantage of this strategy is to avoid the use of specialized biological tests such as the ECT. Further, this strategy could be used in patients with an impaired renal function, given the short half-life of the medications, and the possibility of eliminating tirofiban by ultrafiltration. ${ }^{120}$

\section{Cardiac surgery in patients with previous HIT}

Heparin-induced thrombocytopenia antibodies are transient and usually become undetectable by 100 days (median 50 days) after exposure to heparin. Antibody formation does not recur more often in a patient with a previous history of HIT who is reexposed to heparin..$^{97,121,122}$ Unfractionated heparin is the drug of choice for anticoagulation during $\mathrm{CPB}$ in patients with a history of HIT who no longer have circulating HIT antibodies using one or more sensitive assays (washed platelet activation assay or PF4-heparin antibodies). ${ }^{121,123}$ Importantly, the preoperative or postoperative use of heparin must be avoided completely (catheterization) and alternative methods of anticoagulation should be used.

\section{Cardiac surgery in patients with acute or subacute HIT}

A patient with a recent episode of HIT who has detectable HIT antibodies can develop rapid onset HIT if exposed to UFH. ${ }^{97,122}$ Non-urgent cardiac surgery must be postponed for more than 100 days. If cardiac surgery cannot be delayed and heparin anticoagulation is still contraindicated, several approaches should be considered. The use of heparin-coated CPB circuitry must be avoided. For CABG surgery, an offpump technique should be considered as only one third or one half of the usual heparin dose is needed. Relatively low doses of danaparoid or recombinant hirudin may be used in these cases. ${ }^{124,125}$

The use of a non-heparin anticoagulant depends on patient factors (renal or hepatic failure), availability of non-heparin anticoagulants, and the accessibility of appropriate coagulation monitoring. Specialized monitoring (ECT, anti-Xa activity) is mandatory when using alternative anticoagulants. Recently, recommendations have been published concerning alternative anticoagulant approaches, in order of preference: 1) bivalirudin for intraoperative anticoagulation during CPB (if ECT is available) or during off-pump surgery; 2) lepirudin for intraoperative anticoagulation (if ECT is available and the patient has a normal renal function); 3) UFH plus an antiplatelet agent, eposprestenol or anti GPIIb-IIIa (tirofiban) if ECT monitoring is not available or in the presence of renal insufficiency that precludes lepirudin use; or 4) danaparoid if antifactor Xa monitoring is available. ${ }^{101,119,126}$ Overall a team approach is mandatory, associating the surgeon, anesthesiologist and hematologist.

\section{Management of HIT after cardiac surgery}

When HIT is suspected, UFH as well as low molecular weight heparin, even in small doses used to flush invasive catheters should be stopped urgently and another antithrombotic treatment substituted. Heparin cessation by itself is associated with a high rate of thrombosis $(25 \%$ to $50 \%)$ with $5 \%$ of fatal events. ${ }^{95,96}$ Prophylactic platelet transfusions should be avoided, since infused platelets may react with HIT antibodies and trigger an acute thrombus formation. Vitamin $\mathrm{K}$ antagonists should be avoided in the initial phase of HIT, until platelet count is normalized, since they cause hypercoagulability through protein C depletion within the first hours after administration. 
Screening for venous thrombosis should be performed in order to detect occult lower limb DVT. When acute limb ischemia occurs, surgical thrombectomy may be considered concomitantly with fast-acting alternative anticoagulant therapy.

\section{Conclusion}

Overall, antithrombotic therapy in cardiac surgery raises specific concerns with respect to the choice, dosing, time of onset of antithrombotic agents, and their relative safety and efficacy in this context. As UFH remains widely used in cardiac surgery, HIT is not a rare event, which requires a cautious and multidisciplinary approach.

\section{References}

I Beijering RJ, Ten Cate H, Nurmohamed MT, Ten Cate JW. Anticoagulants and extracorporeal circuits. Semin Thromb Hemost 1997; 23: 225-33.

2 Beguin S, Welzel D, Al Dieri R, Hemker HC. Conjectures and refutations on the mode of action of heparins. The limited importance of anti-factor xa activity as a pharmaceutical mechanism and a yardstick for therapy. Haemostasis 1999; 29:170-8.

3 Despotis GJ, Gravlee G, Filos K, Levy J. Anticoagulation monitoring during cardiac surgery: a review of current and emerging techniques. Anesthesiology 1999; 91: 1122-51.

4 Despotis GJ, Levine V, Joiner-Maier D, Joist JH. A comparison between continuous infusion versus standard bolus administration of heparin based on monitoring in cardiac surgery. Blood Coagul Fibrinolysis 1997; 8: 419-30.

5 Esposito RA, Culliford AT, Colvin SB, Thomas SJ, Lackner H, Spencer FC. Heparin resistance during cardiopulmonary bypass. The role of heparin pretreatment. J Thorac Cardiovasc Surg 1983; 85: 346-53.

6 Bull BS, Korpman RA, Huse WM, Briggs BD. Heparin therapy during extracorporeal circulation. I. Problems inherent in existing heparin protocols. J Thorac Cardiovasc Surg 1975; 69: 674-84.

7 Cohen M. Monitoring anticoagulation during percutaneous coronary interventions. J Thromb Thrombolysis 1995; 1: 285-8.

8 Despotis GJ, Summerfield AL, Joist JH, et al. Comparison of activated coagulation time and whole blood heparin measurements with laboratory plasma anti-Xa heparin concentration in patients having cardiac operations. J Thorac Cardiovasc Surg 1994; 108: 1076-82.

9 Murray DJ, Brosnahan WJ, Pennell B, Kapalanski D, Weiler JM, Olson J. Heparin detection by the activated coagulation time: a comparison of the sensitivity of coagulation tests and heparin assays. J Cardiothorac Vasc Anesth 1997; 11: 24-8.

10 Culliford AT, Gitel SN, Starr N, et al. Lack of correlation between activated clotting time and plasma heparin during cardiopulmonary bypass. Ann Surg 1981; 193: 105-11.

11 Hirsh J, Warkentin TE, Shaughnessy SG, et al. Heparin and low-molecular-weight heparin: mechanisms of action, pharmacokinetics, dosing, monitoring, efficacy, and safety. Chest 2001; 119: 64S-94S.

12 Malviya S. Monitoring and management of anticoagulation in children requiring extracorporeal circulation. Semin Thromb Hemost 1997; 23: 563-7.

13 Despotis GJ, Joist JH. Anticoagulation and anticoagulation reversal with cardiac surgery involving cardiopulmonary bypass: an update. J Cardiothorac Vasc Anesth 1999; 13(4 Suppl 1): 18-29; discussion 36-7.

14 Prisco D, Paniccia R. Point-of-care testing of hemostasis in cardiac surgery. Thromb J 2003; 1 : 1 .

15 Young JA, Kisker CT, Doty DB. Adequate anticoagulation during cardiopulmonary bypass determined by activated clotting time and the appearance of fibrin monomer. Ann Thorac Surg 1978; 26: 231-40.

16 Gravlee GP, Case LD, Angert KC, Rogers AT, Miller GS. Variability of the activated coagulation time. Anesth Analg 1988; 67: 469-72.

17 Jewell AE, Akowuah EF, Suvarna SK, Braidley P, Hopkinson D, Cooper G. A prospective randomised comparison of cardiotomy suction and cell saver for recycling shed blood during cardiac surgery. Eur J Cardiothorac Surg 2003; 23: 633-6.

18 Ranucci M, Cazzaniga A, Soro G, Isgro G, Frigiola $A$, Menicanti $L$. The antithrombin III-saving effect of reduced systemic heparinization and heparin-coated circuits. J Cardiothorac Vasc Anesth 2002; 16: 31620.

19 Johnell M, Elgue G, Larsson R, Larsson A, Thelin S, Siegbahn A. Coagulation, fibrinolysis, and cell activation in patients and shed mediastinal blood during coronary artery bypass grafting with a new heparincoated surface. J Thorac Cardiovasc Surg 2002; 124: 321-32.

20 Baufreton C, de Brux JL, Binuani P, et al. A combined approach for improving cardiopulmonary bypass in coronary artery surgery: a pilot study. Perfusion 2002; 17: 407-13.

21 Banfreton C, de Brux JL. Coagulation, fibrinolysis, and cell activation in patients and in shed mediastinal blood during coronary artery bypass grafting with a new heparin-coated surface. J Thorac Cardiovasc Surg 2003; 126: 2116.

22 Forestier F, Belisle S, Contant C, Harel F, Janvier G, Hardy JF. Reproducibility and interchangeability of 
the Thromboelastograph, Sonoclot and Hemochron activated coagulation time in cardiac surgery. Can J Anesth 2001; 48: 902-10.

23 Hezard N, Metz D, Potron G, et al. Monitoring the effect of heparin bolus during percutaneous coronary angioplasty (PTCA): assessment of three bedside coagulation monitors. Thromb Haemost 1998; 80: 865-6.

24 Welsby IJ, McDonnell E, El-Moalem H, Stafford-Smith $M$, Toffaletti JG. Activated clotting time systems vary in precision and bias and are not interchangeable when following heparin management protocols during cardiopulmonary bypass. J Clin Monit Comput 2002; 17: 287-92.

25 Wendel HP, Heller W, Gallimore MJ, Bantel H, Muller-Beissenhirtz H, Hoffmeister HE. The prolonged activated clotting time (ACT) with aprotinin depends on the type of activator used for measurement. Blood Coagul Fibrinolysis 1993; 4: 41-5.

26 Wang JS, Lin CY, Hung WT, Thisted RA, Karp RB. In vitro effects of aprotinin on activated clotting time measured with different activators. J Thorac Cardiovasc Surg 1992; 104: 1135-40.

27 Najman DM, Walenga JM, Fareed J, Pifarre R. Effects of aprotinin on anticoagulant monitoring: implications in cardiovascular surgery. Ann Thorac Surg 1993; 55: 662-6.

28 Dietrich $W$, Dilthey G, Spannagl $M$, Jochum M, Braun $S L$, Richter JA. Influence of high-dose aprotinin on anticoagulation, heparin requirement, and celite- and kaolin-activated clotting time in heparin-pretreated patients undergoing open-heart surgery. A doubleblind, placebo-controlled study. Anesthesiology 1995; 83: 679-89; discussion 29A-30A.

29 Hunt BJ, Segal H, Yacoub M. Aprotinin and heparin monitoring during cardiopulmonary bypass. Circulation 1992; 86(5 Suppl): II410-2.

30 Bechtel JF, Prosch J, Sievers HH, Bartels C. Is the kaolin or celite activated clotting time affected by tranexamic acid? Ann Thorac Surg 2002; 74: 390-3; discussion 393.

31 Gravlee GP, Whitaker CL, Mark LJ, Rogers AT, Royster RL, Harrison GA. Baseline activated coagulation time should be measured after surgical incision. Anesth Analg 1990; 71: 549-53.

32 Horkay F, Martin P, Rajah SM, Walker DR. Response to heparinization in adults and children undergoing cardiac operations. Ann Thorac Surg 1992; 53: 822-6.

33 run JH, Lee LM, Wahr JA, Fu B, Meyerhoff ME, Yang $V C$. Clinical application of disposable heparin sensors. Blood heparin measurements during open heart surgery. ASAIO J 1995; 41: M661-4.
34 Harloff M, Taraskiewicz J, Fotoubi C. Comparison study of the Hepcon System Four and the Hemostasis Management System. Perfusion 1991; 6: 297-301.

35 Hardy JF, Belisle S, Robitaille D, Perrault J, Roy M, Gagnon L. Measurement of heparin concentration in whole blood with the Hepcon/HMS device does not agree with laboratory determination of plasma heparin concentration using a chromogenic substrate for activated factor X. J Thorac Cardiovasc Surg 1996; 112: 154-61.

36 Despotis GJ, Joist JH, Goodnough LT, Santoro SA, Spitznagel E. Whole blood heparin concentration measurements by automated protamine titration agree with plasma anti-Xa measurements. J Thorac Cardiovasc Surg 1997; 113: 611-3.

37 Koster A, Fischer T, Praus M, et al. Hemostatic activation and inflammatory response during cardiopulmonary bypass: impact of heparin management. Anesthesiology 2002; 97: 837-41.

38 Gravlee GP, Rogers AT, Dudas LM, et al. Heparin management protocol for cardiopulmonary bypass influences postoperative heparin rebound but not bleeding. Anesthesiology 1992; 76: 393-401.

39 Despotis GJ, Joist JH, Hogue CW Jr, et al. The impact of heparin concentration and activated clotting time monitoring on blood conservation. A prospective, randomized evaluation in patients undergoing cardiac operation. J Thorac Cardiovasc Surg 1995; 110: 46-54.

40 Koster A, Fischer T, Gruendel M, et al. Management of heparin resistance during cardiopulmonary bypass: the effect of five different anticoagulation strategies on hemostatic activation. J Cardiothorac Vasc Anesth 2003; 17: 171-5.

41 Levy JH, Despotis GJ, Szlam F, Olson P, Meeker D, Weisinger $A$. Recombinant human transgenic antithrombin in cardiac surgery: a dose-finding study. Anesthesiology 2002; 96: 1095-102.

42 Lemmer JH Jr, Despotis GJ. Antithrombin III concentrate to treat heparin resistance in patients undergoing cardiac surgery. J Thorac Cardiovasc Surg 2002; 123: 213-7.

43 Slaughter TF, Mark JB, El-Moalem H, et al. Hemostatic effects of antithrombin III supplementation during cardiac surgery: results of a prospective randomized investigation. Blood Coagul Fibrinolysis 2001; 12: 25-31.

44 Nicholson SC, Keeling DM, Sinclair ME, Evans RD. Heparin pretreatment does not alter heparin requirements during cardiopulmonary bypass. Br J Anaesth 2001; 87: 844-7.

45 Williams MR, D'Ambra AB, Beck JR, et al. A rando- 
mized trial of antithrombin concentrate for treatment of heparin resistance. Ann Thorac Surg 2000; 70: 873-7.

46 Despotis GJ, Levine V, Joist JH, Joiner-Maier D, Spitznagel E. Antithrombin III during cardiac surgery: effect on response of activated clotting time to heparin and relationship to markers of hemostatic activation. Anesth Analg 1997; 85: 498-506.

47 Hashimoto K, Yamagishi M, Sasaki T, Nakano M, Kurosawa $H$. Heparin and antithrombin III levels during cardiopulmonary bypass: correlation with subclinical plasma coagulation. Ann Thorac Surg 1994; 58: 799-804; discussion 804-5.

48 Donias HW, D'Ancona G, Pande RU, Schimpf D, Kawaguchi AT, Karamanoukian HL. Heparin dose, transfusion rates, and intraoperative graft patency in minimally invasive direct coronary artery bypass. Heart Surg Forum 2003; 6: 176-80.

49 Stein PD, Dalen JE, Goldman S, Theroux P. Antithrombotic therapy in patients with saphenous vein and internal mammary artery bypass grafts. Chest 2001; 119(1 Suppl): 278S-82S.

50 Mayer JE Jr, Lindsay WG, Castaneda W, Nicoloff DM. Influence of aspirin and dipyridamole on patency of coronary artery bypass grafts. Ann Thorac Surg 1981; 31: 204-10.

51 Goldman S, Copeland J, Moritz T, et al. Long-term graft patency (3 years) after coronary artery surgery. Effects of aspirin: results of a VA Cooperative study. Circulation 1994; 89: 1138-43.

52 Stein PD, Schunemann HJ, Dalen JE, Gutterman D. Antithrombotic therapy in patients with saphenous vein and internal mammary artery bypass grafts: the Seventh ACCP Conference on Antithrombotic and Thrombolytic Therapy. Chest 2004; 126(3 Suppl): 600S-8S.

53 Goldman S, Copeland J, Moritz T, et al. Improvement in early saphenous vein graft patency after coronary artery bypass surgery with antiplatelet therapy: results of a Veterans Administration Cooperative Study. Circulation 1988; 77: 1324-32.

54 Goldman S, Copeland J, Moritz T, et al. Saphenous vein graft patency 1 year after coronary artery bypass surgery and effects of antiplatelet therapy. Results of a Veterans Administration Cooperative Study. Circulation 1989; 80: 1190-7.

55 Gavaghan TP, Gebski V, Baron DW. Immediate postoperative aspirin improves vein graft patency early and late after coronary artery bypass graft surgery. A placebo-controlled, randomized study. Circulation 1991; 83: 1526-33.

56 McEnany MT, Salzman EW, Mundth ED, et al. The effect of antithrombotic therapy on patency rates of saphenous vein coronary artery bypass grafts. J

Thorac Cardiovasc Surg 1982; 83: 81-9.

57 Brown BG, Cukingnan RA, DeRouen T, et al. Improved graft patency in patients treated with platelet-inhibiting therapy after coronary bypass surgery. Circulation 1985; 72: 138-46.

58 Sharma GV, Khuri SF, Josa M, Folland ED, Parisi $A F$. The effect of antiplatelet therapy on saphenous vein coronary artery bypass graft patency. Circulation 1983; 68(3 Pt 2): II218-21.

59 Chesebro JH, Clements IP, Fuster V, et al. A platelet-inhibitor-drug trial in coronary-artery bypass operations: benefit of perioperative dipyridamole and aspirin therapy on early postoperative vein-graft patency. N Engl J Med 1982; 307: 73-8.

60 Eagle KA, Guyton RA, Davidoff R, et al. ACC/ AHA 2004 guideline update for coronary artery bypass graft surgery: summary article: a report of the American College of Cardiology/American Heart Association Task Force on Practice Guidelines (Committee to Update the 1999 Guidelines for Coronary Artery Bypass Graft Surgery). Circulation 2004; 110: 1168-76.

61 Kallis P, Tooze JA, Talbot S, Cowans D, Bevan DH, Treasure $T$. Pre-operative aspirin decreases platelet aggregation and increases post-operative blood loss--a prospective, randomised, placebo controlled, doubleblind clinical trial in 100 patients with chronic stable angina. Eur J Cardiothorac Surg 1994; 8: 404-9.

62 Sethi GK, Copeland JG, Goldman S, Moritz T, Zadina $K$, Henderson WG. Implications of preoperative administration of aspirin in patients undergoing coronary artery bypass grafting. Department of Veterans Affairs Cooperative Study on Antiplatelet Therapy. J Am Coll Cardiol 1990; 15: 15-20.

63 Taggart DP, Siddiqui A, Wheatley DJ. Low-dose preoperative aspirin therapy, postoperative blood loss, and transfusion requirements. Ann Thorac Surg 1990; 50: 424-8.

64 Belisle S, Hardy JF. Hemorrhage and the use of blood products after adult cardiac operations: myths and realities. Ann Thorac Surg 1996; 62: 1908-17.

65 Dacey LJ, Munoz JJ, Johnson ER, et al. Effect of preoperative aspirin use on mortality in coronary artery bypass grafting patients. Ann Thorac Surg 2000; 70: 1986-90.

66 Mangano DT; Multicenter Study of Perioperative Ischemia Research Group. Aspirin and mortality from coronary bypass surgery. N Engl J Med 2002; 347 : 1309-17.

67 Fox KA, Mehta SR, Peters $R$, et al. Benefits and risks of the combination of clopidogrel and aspirin in patients undergoing surgical revascularization 
for non-ST-elevation acute coronary syndrome: the Clopidogrel in Unstable angina to prevent Recurrent ischemic Events (CURE) Trial. Circulation 2004; 110: 1202-8.

68 Englberger L, Faeh B, Berdat PA, Eberli F, Meier B, Carrel $T$. Impact of clopidogrel in coronary artery bypass grafting. Eur J Cardiothorac Surg 2004; 26 : 96-101.

69 Cosgrove DM 3rd, Heric B, Lytle BW, et al. Aprotinin therapy for reoperative myocardial revascularization: a placebo-controlled study. Ann Thorac Surg 1992; 54: 1031-6; discussion 1036-8.

70 Havel M, Grabenwoger F, Schneider J, et al. Aprotinin does not decrease early graft patency after coronary artery bypass grafting despite reducing postoperative bleeding and use of donated blood. J Thorac Cardiovasc Surg 1994; 107: 807-10.

71 Levy JH, Pifarre R, Schaff HV, et al. A multicenter, double-blind, placebo-controlled trial of aprotinin for reducing blood loss and the requirement for donorblood transfusion in patients undergoing repeat coronary artery bypass grafting. Circulation 1995; 92 : 2236-44.

72 Vander Salm TJ, Kaur S, Lancey RA, et al. Reduction of bleeding after heart operations through the prophylactic use of epsilon-aminocaproic acid (French). J Thorac Cardiovasc Surg 1996; 112: 1098-107.

73 Horrow JC, Van Riper DF, Strong MD, Brodsky I, Parmet JL. Hemostatic effects of tranexamic acid and desmopressin during cardiac surgery. Circulation 1991; 84: 2063-70.

74 Horrow JC, Hlavacek J, Strong MD, et al. Prophylactic tranexamic acid decreases bleeding after cardiac operations. J Thorac Cardiovasc Surg 1990; 99: 70-4.

75 Jares M, Vanek T, Straka Z, Brucek P. Tranexamic acid reduces bleeding after off-pump coronary artery bypass grafting. J Cardiovasc Surg (Torino) 2003; 44: 205-8.

76 Pleym H, Stenseth R, Wabba A, Bjella L, Karevold A, Dale $O$. Single-dose tranexamic acid reduces postoperative bleeding after coronary surgery in patients treated with aspirin until surgery. Anesth Analg 2003; 96: 923-8.

77 Hekmat K, Zimmermann T, Kampe S, et al. Impact of tranexamic acid vs. aprotinin on blood loss and transfusion requirements after cardiopulmonary bypass: a prospective, randomised, double-blind trial. Curr Med Res Opin 2004; 20: 121-6.

78 Zimmermann N, Kienzle P, Weber AA, et al. Aspirin resistance after coronary artery bypass grafting. J Thorac Cardiovasc Surg 2001; 121: 982-4.

79 Zimmermann N, Wenk A, Kim U, et al. Functional and biochemical evaluation of platelet aspirin resistance after coronary artery bypass surgery. Circulation 2003; 108: 542-7.

80 Lim E, Cornelissen J, Routledge T, et al. Clopidogrel did not inhibit platelet function early after coronary bypass surgery: a prospective randomized trial. J Thorac Cardiovasc Surg 2004; 128: 432-5.

81 Goblke-Barwolf C, Acar J, Oakley C, et al. Guidelines for prevention of thromboembolic events in valvular heart disease. Study Group of the Working Group on Valvular Heart Disease of the European Society of Cardiology. Eur Heart J 1995; 16: 1320-30.

82 Bonow RO, Carabello B, de Leon AC Jr, et al. Guidelines for the management of patients with valvular heart disease: executive summary. A report of the American College of Cardiology/American Heart Association Task Force on Practice Guidelines (Committee on Management of Patients with Valvular Heart Disease). Circulation 1998; 98: 1949_ 84.

83 Salem DN, Stein PD, Al-Abmad A, et al. Antithrombotic therapy in valvular heart disease-native and prosthetic: the Seventh ACCP Conference on Antithrombotic and Thrombolytic Therapy. Chest 2004; 126: 457S-82S.

84 Gherli T, Colli A, Fragnito C, et al. Comparing warfarin with aspirin after biological aortic valve replacement: a prospective study. Circulation 2004; 110 : 496-500.

85 Montalescot G, Polle V, Collet JP, et al. Low molecular weight heparin after mechanical heart valve replacement. Circulation 2000; 101: 1083-6.

86 Fanikos J, Tsilimingras K, Kucher N, Rosen AB, Hieblinger MD, Goldhaber SZ. Comparison of efficacy, safety, and cost of low-molecular-weight heparin with continuous-infusion unfractionated heparin for initiation of anticoagulation after mechanical prosthetic valve implantation. Am J Cardiol 2004; 93: 247-50.

87 Tinmouth AH, Morrow BH, Cruickshank MK, Moore $P M$, Kovacs MJ. Dalteparin as periprocedure anticoagulation for patients on warfarin and at high risk of thrombosis. Ann Pharmacother 2001; 35: 669-74.

88 Singer DE, Albers GW, Dalen JE, Go AS, Halperin $J L$, Manning WJ. Antithrombotic therapy in atrial fibrillation: the Seventh ACCP Conference on Antithrombotic and Thrombolytic Therapy. Chest 2004; 126(3 Suppl): 429S-56S.

89 Goldhaber SZ, Hirsch DR, MacDougall RC, Polak JF, Creager MA, Cohn LH. Prevention of venous thrombosis after coronary artery bypass surgery (a randomized trial comparing two mechanical prophylaxis strategies). Am J Cardiol 1995; 76: 993-6. 
90 Rao G, Zikria EA, Miller WH, Samadani SR, Ford $W B$. Incidence and prevention of pulmonary embolism after coronary artery surgery. Vasc Surg 1975; 9: $37-45$.

91 Josa M, Siouffi SY, Silverman AB, Barsamian EM, Khuri SF, Sharma GV. Pulmonary embolism after cardiac surgery. J Am Coll Cardiol 1993; 21: 990-6.

92 Parenti C. Pulmonary embolism after coronary artery bypass surgery. Crit Care Nurs Q 1994; 17: 48-50.

93 Ambrosetti M, Salerno M, Zambelli M, Mastropasqua $F$, Tramarin R, Pedretti RF. Deep vein thrombosis among patients entering cardiac rehabilitation after coronary artery bypass surgery. Chest 2004; 125 : 191-6.

94 Warkentin TE, Chong BH, Greinacher A. Heparininduced thrombocytopenia: towards consensus. Thromb Haemost 1998; 79: 1-7.

95 Warkentin TE. Heparin-induced thrombocytopenia: pathogenesis and management. Br J Haematol 2003; 121: 535-55.

96 Warkentin TE, Kelton JG. A 14-year study of heparininduced thrombocytopenia. Am J Med 1996; 101: 502-7.

97 Warkentin TE, Kelton JG. Temporal aspects of heparin-induced thrombocytopenia. N Engl J Med 2001; 344: 1286-92.

98 Singer RL, Mannion JD, Bauer TL, Armenti FR, Edie $R N$. Complications from heparin-induced thrombocytopenia in patients undergoing cardiopulmonary bypass. Chest 1993; 104: 1436-40.

99 Walls JT, Curtis JJ, Silver D, Boley TM, Schmaltz RA, Nawarawong $W$. Heparin-induced thrombocytopenia in open heart surgical patients: sequelae of late recognition. Ann Thorac Surg 1992; 53: 787-91.

100 Francis JL, Palmer GJ 3rd, Moroose R, Drexler A. Comparison of bovine and porcine heparin in heparin antibody formation after cardiac surgery. Ann Thorac Surg 2003; 75: 17-22.

101 Warkentin TE, Greinacher A. Heparin-induced thrombocytopenia: recognition, treatment, and prevention: the Seventh ACCP Conference on Antithrombotic and Thrombolytic Therapy. Chest 2004; 126(3 Suppl): 311S-37S.

102 Pouplard C, May M, Regina S, Maakaroun A, Fusciardi J, Gruel $\Upsilon$. Changes in the platelet count after cardiopulmonary bypass can efficiently predict the development of pathogenic heparin-dependent antibodies. Blood 2002; 100: 16A-17A.

103 Warkentin TE, Roberts RS, Hirsh J, Kelton JG. An improved definition of immune heparin-induced thrombocytopenia in postoperative orthopedic patients. Arch Intern Med 2003; 163: 2518-24.

104 Martin JF, Daniel TD, Trowbridge EA. Acute and chronic changes in platelet volume and count after cardiopulmonary bypass induced thrombocytopenia in man. Thromb Haemost 1987; 57: 55-8.

105 Lin JC, Lewis BE, Steen LH, et al. Patency of coronary artery bypass grafts in patients with heparininduced thrombocytopenia. Am J Cardiol 2002; 89: 979-81.

106 Hong AP, Cook DJ, Sigouin CS, Warkentin TE. Central venous catheters and upper-extremity deep-vein thrombosis complicating immune heparin-induced thrombocytopenia. Blood 2003; 101: 3049-51.

107 Warkentin TE. Platelet count monitoring and laboratory testing for heparin-induced thrombocytopenia. Arch Pathol Lab Med 2002; 126: 1415-23.

108 Warkentin TE, Heddle NM. Laboratory diagnosis of immune heparin-induced thrombocytopenia. Curr Hematol Rep 2003; 2: 148-57.

109 Koster A, Crystal GJ, Kuppe H, Mertzlufft F. Acute heparin-induced thrombocytopenia type II during cardiopulmonary bypass. J Cardiothorac Vasc Anesth 2000; 14: 300-3.

110 Koster A, Hansen R, Kuppe H, Hetzer R, Crystal GJ, Mertzlufft $F$. Recombinant hirudin as an alternative for anticoagulation during cardiopulmonary bypass in patients with heparin-induced thrombocytopenia type II: a l-year experience in 57 patients. J Cardiothorac Vasc Anesth 2000; 14: 243-8.

111 Koster A, Hansen R, Grauban O, et al. Hirudin monitoring using the TAS ecarin clotting time in patients with heparin-induced thrombocytopenia type II. J Cardiothorac Vasc Anesth 2000; 14: 249-52.

112 Greinacher $A$. The use of direct thrombin inhibitors in cardiovascular surgery in patients with heparininduced thrombocytopenia. Semin Thromb Hemost 2004; 30: 315-27.

113 Vasquez JC, Vichiendilokkul A, Mabmood S, Baciewicz $F A J r$. Anticoagulation with bivalirudin during cardiopulmonary bypass in cardiac surgery. Ann Thorac Surg 2002; 74: 2177-9.

114 Davis Z, Anderson R, Short D, Garber D, Valgiusti A. Favorable outcome with bivalirudin anticoagulation during cardiopulmonary bypass. Ann Thorac Surg 2003; 75: 264-5.

115 Koster A, Chew D, Grundel M, Bauer M, Kuppe H, Spiess BD. Bivalirudin monitored with the ecarin clotting time for anticoagulation during cardiopulmonary bypass. Anesth Analg 2003; 96: 383-6.

116 Kawada T, Kitagawa H, Hoson M, Okada $\Upsilon$, Shiomura J. Clinical application of argatroban as an alternative anticoagulant for extracorporeal circulation. Hematol Oncol Clin North Am 2000; 14: 445-57. 
117 Magnani H, Beijering R, Ten Cate J, Chong BH.

Orgaran anticoagulation for cardiopulmonary bypass

in patient with heparin-induced thrombocytopenia. In: Pifarre R (Ed.). New Anticoagulants for the Cardiovascular Patient. Philadelphia: Hanley \& Belfus; 1997: 487-500.

118 Warkentin TE. Pork or beef? (Editorial). Ann Thorac Surg 2003; 75: 15-6.

119 Koster A, Meyer O, Fischer T, et al. One-year experience with the platelet glycoprotein IIb/IIIa antagonist tirofiban and heparin during cardiopulmonary bypass in patients with heparin-induced thrombocytopenia type II. J Thorac Cardiovasc Surg 2001; 122: 1254-5.

120 Koster A, Chew D, Merkle F, et al. Extracorporeal elimination of large concentrations of tirofiban by zero-balanced ultrafiltration during cardiopulmonary bypass: an in vitro investigation. Anesth Analg 2004; 99: 989-92.

121 Potzsch B, Klovekorn WP, Madlener K. Use of heparin during cardiopulmonary bypass in patients with a history of heparin-induced thrombocytopenia. N Engl J Med 2000; 343: 515.

122 Lubenow N, Kempf R, Eichner A, Eichler P, Carlsson $L E$, Greinacher $A$. Heparin-induced thrombocytopenia: temporal pattern of thrombocytopenia in relation to initial use or reexposure to heparin. Chest 2002; 122: 37-42.

123 Potzsch B, Madlener K. Management of cardiopulmonary-bypass anticoagulation in patient with heparin-induced thrombocytopenia. In: Warkentin TE, Greinacher A (Eds). Heparin-Induced Thrombocytopenia. New York: Marcel Dekker; 2001: 429-44.

124 Koster A, Kuppe H, Crystal GJ, Mertzlufft F. Cardiovascular surgery without cardiopulmonary bypass in patients with heparin-induced thrombocytopenia type II using anticoagulation with recombinant hirudin. Anesth Analg 2000; 90: 292-8.

125 Warkentin TE, Dunn GL, Cybulsky IJ. Off-pump coronary artery bypass grafting for acute heparininduced thrombocytopenia. Ann Thorac Surg 2001; 72: 1730-2.

126 Warkentin TE, Greinacher A. Heparin-induced thrombocytopenia and cardiac surgery. Ann Thorac Surg 2003; 76: 2121-31. 